\title{
ANNOUNCEMENT
}

\section{The Marie Selby Botanical Gardens, Florida, USA}

\section{The journal Selbyana}

Selbyana, the journal of the Marie Selby Botanical Gardens, is devoted to the publication of original research on tropical plants, especially epiphytes. The journal emphasizes taxonomic and floristic treatments, but also includes research on anatomy, cytology, systematics, phylogeny, ecology, biogeography, and physiology of tropical plants. Selbyana is available for the publication of research of the Gardens' staff as well as outside contributors. All manuscripts submitted are reviewed by at least two specialists in the subject.

Authors will not be assessed mandatory page charges, but contribution towards the cost of publication is encouraged. Information to contributors is printed on the inside back cover of each issue. Authors may write for information or submit manuscripts to Dr Natini M. Nadkarni, Editor, Marie Selby Botanical Gardens, 811 South Palm Avenue, Sarasota, Florida 34236 , USA.

Selbyana is published annually. Subscription price is $\$ 55.00$ per volume for all libraries and institutions (includes normal shipping). Personal subscriptions are available at $\$ 35.00$ per volume. For subscription information, and for information about the availability of back issues, contact Mrs Ruby Hollis, Marie Selby Botanical Gardens, 811 South Palm Avenue, Sarasota, Florida 34236. Telephone (813) 366-5730.

\section{Epiphyte Symposium}

In keeping with its goals of research and conservation, the Marie Selby Botanical Gardens in celebration of its fifteenth anniversary will hold an international symposium entitled: 'The Biology and Conservation of Epiphytes' in Sarasota, Florida, USA, on 5-8 May 1991. This Symposium will be modelled after the first Tropical Epiphyte Symposium held at the Selby Gardens in September 1985. The major goal of the Symposium is to foster exchange of information on epiphytes across lines of individual disciplines, geographical areas, and plant taxa. Invited and contributed papers will address botanical, ecological, and horticultural topics pertaining to tropical and temperate vascular and non-vascular epiphytes, including their systematics, ecology, interactions with canopy fauna, physiology, conservation, micropropagation, and cultural management in glass houses and botanical gardens. A large collection of living specimens of the Orchidaceae, Bromeliaceae, Araceae, Gesneriaceae, and Pteridophyta, as well as many other tropical vascular plants, is maintained at Selby Gardens. The Symposium is open to all biologists and horticulturalists interested in epiphytes.

For additional information on this Symposium, write to Dr Nalini M. Nadkarni, Director of Research, Marie Selby Botanical Gardens, 811 South Palm Avenue, Sarasota, Florida 34236, USA. 